\title{
O APRIMORAMENTO DA AQUISIÇÃO DE VOCABULÁRIO DE ALUNOS DE LÍNGUA INGLESA ATRAVÉS DO USO DE APLICATIVOS
}

Kleiton BORGES

Pós-graduação em Linguística - Universidade Federal do Pará

\begin{abstract}
RESUMO: Este trabalho tem por objetivo mostrar os resultados de uma pesquisa de campo desenvolvida emum curso de língua inglesa da Universidade Federal do Pará (UFPA)com o escopo de saber se os alunos usavamaplicativos em computadores esmartphonescomo auxílio na aprendizagemde novosvocabulários, adquirindo conhecimento, também,dos tipos de suas próprias estratégias paraeste tipo de aprendizagem.Para isto, a pesquisa se deucom uma turma do segundo nível de língua inglesa, pela qual foram submetidos aum questionário comquestões estruturadasesemi-estruturadas.Com o avanço da tecnologia, da Internet e dos novos dispositivos, instituições e estudantes vêm encontrando maneiras viáveis para um novo modelo de aprendizagem de língua estrangeira dentro e fora da sala de aula. Parte-se do pressuposto de queos alunos possuemo hábitode usar aplicativospara aprendernovos vocabuláriosda língua inglesa, tornando-os autônomos e encontrandosuas própriasestratégias de aprendizagem.Para isso, fez-se necessário buscar referenciais teóricos sobre Aprendizagem de Língua Mediada por Computador (CALL)em Leffa (2006) e Hubbard (2009), sobre os conceitos de aplicativos em Guerreiro (2010) ePorto (2012), sobre aspectos de aquisição de vocabulário em língua inglesa emSapucaia (2008) eLemetyinen (2012)esobre estratégias de aprendizagem em Meireles (2005) e Magno e Silva e Santos (2014).Como resultado, a maioria dos alunos possuem conhecimento e domínio das tecnologias atuais e que, através deles, eles podem utilizar suas próprias estratégias de aprendizagem na aquisição de novos vocabulários, tanto dentro quanto fora da sala de aula. Concluiu-se que o uso de aplicativos são ferramentas valiosas, tanto para alunos quanto para professores, pois estamos sempre caminhando em direção à era digital e em constante evolução tecnológica, com crescimento acelerado de usuários e uma grande tendência de modificações nas estruturas educacionais. PALAVRAS-CHAVE:Tecnologia; Aplicativos; Aquisição de vocabulário.
\end{abstract}

ABSTRACT:This paper has the aim to show the results of a field research developed in anEnglish language course at Federal University of Pará (UFPA) with the objective to know if students used applications in computers and smartphones as anaid in learning of new vocabularies, acquiring knowledge, also, types of their own strategies for this kind of learning. For this, the research happened with an English class in level two, which all students were submitted to a questionnaire with structured and half structured questions. With the advance of technology, Internet and new devices, institutions and students has been finding viable ways for a new learning model of foreign language inside and outside classroom. We suppose that students have the habit to use applications for learning new vocabulary in English language, making them autonomous and finding their own learning strategies. Thus, it was necessary to search theoretical references about Computer-Assisted Language Learning (CALL) in Hubbard (2009) andLeffa (2006), about concepts of applications in Guerreiro (2010) andPorto (2012), about aspects of vocabulary acquisition in English language in Lemetyinen (2012) andSapucaia (2008) and about learning strategies inMeireles (2005) and Magnoe Silva and Santos (2014). As results, the most students have knowledge and mastery of current technologies and, through them, they could use their own learning strategies in acquisition of new vocabularies, both inside and outside classroom. It was concluded that the use of applications are valuable tools, both for students and teachers, because we are always walking toward the digital age and in constant technological 
evolution, with accelerated user growth and a major trend towards changes in educational structures.

KEYWORDS:Technology; Applications; Vocabulary acquisition.

\section{Introdução}

Com o avanço da Aprendizagem de Língua Mediada por Computador (CALL) e com a demanda crescente do uso da Internet, instituições de ensino estão encontrando maneiras viáveis para um novo modelo de aprendizagem de língua estrangeira (LE) e que podem ser encontradas dentro e fora da sala de aula. Hoje em dia, a tecnologia encontrada em novos dispositivos (como computadores pessoais e smartphones) está ganhando espaço maior no meio social e, inevitavelmente, o seu uso é notável no contexto escolar, onde seu manuseio é praticado de uma forma rápida pelos seus usuários, com uma convicção de aprendizagem incrível com o seu uso frequente.

Além disso, os variados aplicativos, existentes em computadores e smartphones, dão aos seus usuários a possibilidade de estudar uma LE, oferecer serviços como consultas de mapas e a previsão do tempo, sobre informações atualizadas do que acontece no mundo, a possibilidade de comunicação com pessoas de várias partes do mundo e a possibilidade de entretenimento como jogos.

As hipóteses levantadas neste trabalho foram de que alunos de línguas estrangeiras usavam estas ferramentas tecnológicas para auxiliá-los na aprendizagem de novos vocabulários, usando tanto dentro da sala de aula quanto fora. Também levantou-se a hipótese de que eles usavam aplicativos neste dispositivos para aprender novos vocabulários por conta própria, utilizando suas próprias estratégias de aprendizagem.

Portanto, este trabalho tem por objetivo mostrar os resultados de uma pesquisa de campo desenvolvida em um curso de língua inglesa na Universidade Federal do Pará (UFPA) com o escopo de saber se os alunos usavam aplicativos em computadores e smartphones como auxílio na aprendizagem de novos vocabulários, apresentando também os tipos de estratégias de aprendizagem. Para tanto, este trabalho é apresentado em três partes: fundamentação teórica, metodologia (contexto de pesquisa, participantes, instrumentos de pesquisa, procedimentos de coleta de dados) e análise e discussão dos dados.

\section{Aprendizagem de Língua Mediada por Computador}

A Aprendizagem de Língua Mediada por Computador ${ }^{1}$ (CALL) é uma área de pesquisas com o objetivo de elencar os fatores que os computadores podem influenciar no ensino e aprendizagem de línguas (LEFFA, 2006, p. 2). Segundo Beatty (2003 apud Hubbard, 2009), CALL é definida como "qualquer processo pela qual um aprendente usa um computador e, como resultado, aprimora a sua língua".

\footnotetext{
${ }^{1}$ Computer-Assisted Language Learning. (esta e demais traduções são de minha responsabilidade)
} 
Uns dos exemplos em que se teve um grande avanço nesta área foram as criações da computação multimídia, a Internet e a tão usada World Wide Web, pois deram grandes passos para as aplicações da aprendizagem de línguas mediada por computador. CALL oferece uma grande variedade de programas, variedades educacionais, recursos, aplicações, incluindo também jogos, exercícios e a possibilidade de aprimorar as quatro habilidades da língua alvo, dentre outros.

Leffa (2006) e Hubbard (2009) mencionam a historicidade desta área. Em meados dos anos 60 e 70, algumas universidades possuíam laboratórios específicos para o ensino de LE e que eram interligadas sempre a um grande e único computador central, que eram os que ditavam as atividades. O que predominava nesta época, no que diz respeito ao ensino de LE, eram basicamente os exercícios estruturalistas, com aspectos gramaticais precisos da línguaalvo, com exercícios com "estruturas básicas da língua". Como exemplo, os alunos eram submetidos a atividades como passar uma oração afirmativa para negativa ou interrogativa, a troca de certos verbos nos tempos verbais para o futuro ou para o passado, dentre outros exercícios em que a repetição era necessária para a aquisição da nova LE.

Por muito tempo esse movimento estruturalista da língua era muito criticado por autores da época (e nos dias atuais) por apresentar uma didática "reforçada" para a formação dos hábitos linguísticos, pois se dizia que o aluno perdia praticamente a vontade e interesse em estudar por conta própria depois de uma aula repleta de repetições e esforços. Nesse aspecto, predominava o "CALL behaviorista", mas não como uma forma de ensino errônea, mas sim, era a "melhor forma" de aprendizagem de línguas naquela época, o que rendia, também, bons resultados.

Depois disso, em meados dos anos 80, os microcomputadores e os computadores pessoais começaram a serem introduzidos nas universidades, escolas do ensino fundamental e médio dos EUA, iniciando a época do "CALL comunicativo". As atividades e exercícios propostos ganharam dinamismos com o uso do computador, como, por exemplo, jogos gráficos, produção textual, simulações gráficas etc. Mas isso não quer dizer que a prática behaviorista tenha terminado, e sim, foi incrementado o método comunicativo no ensino de LE mediada pelo computador, o que pôde ser utilizado como material autêntico nas aulas. Diante disso, a manipulação de textos e sentenças, presentes nos $C D-R O M s$ dos anos 90, foi a época em que mais foram usados para cursos de línguas, incluindo enciclopédias, gráficos, textos, áudios e vídeos, sendo que o usuário poderia estudar fora das salas de aula. O estudo autônomo, feito por esses alunos, sem a presença do professor e fora da área escolar, seria uma das vantagens de aprimoramento da língua e, agindo dessa maneira, ganhava recursos extras, como materiais autênticos e de menores gastos (HUBBARD, 2009).

E por último e não obstante desta mesma época é introduzida a metodologia do ensino de línguas estrangeiras através do "CALL integrativo", onde podemos perceber que, com o avanço da tecnologia e da Internet nos dias atuais, encontramos possibilidades de trabalhar dentro e fora da sala de aula as quatro habilidades da língua-alvo (escuta, escrita, leitura e fala). Como exemplo de atividade desta época existiam as gravações da própria voz e a possibilidade de escutá-la repetidamente. Com a ajuda da Internet, podemos nos integrar com a mesma buscando comunidades autênticas para a troca de experiências com pessoas em várias partes do mundo, com propósitos do ensino de línguas e a busca da aprendizagem. 
Mesmo com todas essas possibilidades, CALL possui seus lados positivos e negativos, pois está em constante mudança, é complexo e dinâmico. Para esta área, novos conhecimentos devem ser adquiridos e devem-se buscar novas habilidades na sua incorporação nas diversas outras áreas. Uns dos problemas relacionados a esta área está em relação aos materiais custeados para usuários, falta de manuseio de certos sítios, de não saber lidar com as novas tecnologias e ao acesso aos conteúdos inapropriados aos estudos.

Este tipo de tecnologia tem sido gradualmente inserido na área da educação, pois a utilização de seus recursos possibilita aos usuários contextos diversos e específicos de aprendizagem, tendo efeitos e preferência de uso, além de ser aplicado para facilitar o enriquecimento da língua e suporte em diversas perspectivas. Além desta área poder ser bastante útil para o aprimoramento das habilidades específicas da LE, também possibilita o estímulo da motivação dos aprendentes, auxiliando-os e os engajando na sua aprendizagem de forma autônoma.

\section{O ensino através do computador}

A tecnologia atual está avançando de uma forma rápida, mostrando novos equipamentos, novos dispositivos e melhores condições de ensino-aprendizagem dentro da sala de aula. Muitas são as vantagens que podemos encontrar com a viabilização desses avanços, pois com o avanço da Internet, hoje podemos aprender, por nós mesmo, qualquer LE através de vários sites de treinamentos, com exercícios específicos e uma interação motivacional incrível para seus usuários.

No campo da educação, as perspectivas do ensino através do computador estão cada vez mais importantes para o país e o mundo, pois há interação no meio populacional de forma rápida, integrada e presencial, modificando profundamente as formas de ensino-aprendizagem nas salas de aula. Temos grandes vantagens nos estudos online, sítios que proporcionam exatamente aquilo que poderíamos pagar em escolas específicas de inglês, proporcionando vários materiais, animações, atividades e correções adequadas para o aprimoramento educacional. Moran comenta em seu trabalho sobre o futuro da educação online no Brasil:

Temos cursos prontos, com instruções precisas para o aluno, baseados em materiais online, em cases, animações, pequenos vídeos e atividades que o aluno realiza durante um período determinado e que envia os resultados das atividades a um centro que as corrige, normalmente, de forma automática e atribui um conceito que permite o avanço do aluno para uma nova etapa. A grande vantagem destes cursos é a flexibilidade de tempo. $\mathrm{O}$ aluno pode começar e terminar dentro do seu próprio ritmo. $\mathrm{O}$ curso pode acontecer a qualquer momento. Não precisa reunir uma turma específica, com determinado número de alunos. Isso facilita para a instituição e para o aluno (MORAN, 2005, p. 3).

Em concordância com Kern (2006), a funcionalidade atual dos novos dispositivos (tablets, flash drives, netbooks etc.) está crescendo de uma forma rápida e que nesse aspecto teremos que acompanhar o ritmo dessas mudanças, pois precisamos nos adequar às novas informações e comunicações desenvolvidas, especificamente em computadores. Nesse 
contexto, quem está dentro desse ritmo, pode-se dizer que está atualizado, trocando informações e se comunicando de forma adequada, pois sabemos que, hoje, até professores precisam ter conhecimento das novas tecnologias para aprimorar seus planos de aulas. Rodrigues, em sua proposta de curso com inserção do computador para aulas, enfatiza:

A crescente demanda em que estamos inseridos na última década, junto à informatização de todos os setores do mundo atual, vem exigindo de todos os profissionais, a inserção da tecnologia em todos os segmentos e trabalhos, aqueles que não se inovam, correm o risco de ficarem obsoletos e falirem, dentre esses segmentos, encontra-se a educação, nesse mundo informatizado, muitos são os entraves para iniciação do trabalho educativo com informática, agonizando, a educação luta contra sua criação - o computador (RODRIGUES, 2005, p. 2).

$\mathrm{O}$ autor menciona que professores e profissionais devem estar atrelados ao novo mundo da tecnologia, mas não somente em uma profissão, mas sim em todos os tipos de segmentos de trabalho, pois corremos a grande possibilidade de ficarmos desatualizados das informações que vêm sendo postas no mundo atual. Porém, a educação está entre nós e como vários outros setores, ela pode ser repassada de forma viável e criativa aos aprendentes de LE por causa do computador e seus vários recursos vantajosos educativos.

\section{Aplicativos}

Aplicativos são cada vez mais populares e tornaram-se muito importantes nos últimos anos. Com a crescente demanda de usuários que manipulam instrumentos inteligentes que fazem multitarefas, as grandes empresas têm se esforçado para lançar smartphones melhores no mercado atual, mostrando benefícios consideráveis para consumidores. Hoje em dia encontra-se variedades de aplicativos no meio virtual, apresentando versões pagas ou versões gratuitas, de acordo com suas funcionalidades e objetivos.

São poucos os conceitos sobre o que são aplicativos na fundamentação teórica, porém, podemos citar alguns deles. No aplicativo Dictionary English-Portuguese Free (2014), encontrado na plataforma Google Play, afirma que "aplicativo é um programa de computador projetado para executar uma tarefa específica para um usuário ou outro aplicativo". Wikipedia (2014) menciona que aplicativos são programas de computador com o propósito de auxiliar usuários a fazer tarefas específicas, associado a um sistema de processamento. Dentre esses aplicativos, podem ser citados Microsoft Office, Adobe Reader, Internet Explorer, Google Chrome etc.

De acordo com Guerreiro (2010), os aplicativos são geralmente instalados em smartphones e são uma espécie de facilidade para os usuários, proporcionando acesso direto como serviços de notícias, informações meteorológicas, jogos, serviços de mapas etc. Já de acordo com Porto (2012), "aplicativos móveis são programas que executam objetivos específicos em smartphones e tablets". Este autor ainda classifica os aplicativos em quatro tipos: 
1 - Serviço: dar informações e conteúdo como previsões meteorológicas e pesquisas relacionadas a procura de um determinado endereço em mapas.

2 - Informações: a possibilidade de acesso a conteúdo atualizado em tempo real para quem possui permanente utilidades, como lojas de compras, telefones úteis etc.

3 - Comunicação: permite a interação entre pessoas, como é o caso das redes sociais atuais.

4 - Entretenimento: é a indústria dos jogos que oferece como aplicativos em smartphones e possui o maior volume de negócios entre todos os segmentos do entretenimento.

A interação entre usuários e estes dispositivos por meio de aplicativos possibilita manter contato com outras pessoas, estar ciente das notícias do dia, encontrar um endereço específico, ficar ciente da previsão do dia, acessar redes sociais como Facebook e Twitter e também possibilita estudar uma LE pretendida.

Como exemplo de aplicativo, citamos o conhecido WhatsApp, que hoje em dia é usado para interações virtuais com pessoas e como uma plataforma para o ensino e aprendizagem de LE, cabendo ao professor e a instituição de ensino como trabalhá-la. Ferreira diz que:

WhatsApp Messenger é um aplicativo de multiplataforma (app é diminutivo para "aplicativo") que permite-se trocar mensagens através de celulares sem pagar pelo SMS, somente tendo uma conexão $3 G$ ou Wi-Fi (Wi-Fi é uma tecnologia popular que permite um dispositivo eletrônico trocar dados ou conectar a Internet sem fio usando ondas de rádio) ${ }^{2}$ (FERREIRA, 2013, p. $13)$.

Com este aplicativo, pode-se promover a motivação e auxiliar alunos para a aprendizagem de LE. Na proposta de Ferreira para produção escrita, ele sugere uma atividade de escrita em grupo usando um aplicativo em smartphones, chamado Pictionary, "um dicionário onde a definição de uma palavra é exibida na forma de um desenho ou fotografia ..." $^{3}$.

Através das definições de aplicativos, aprendentes de LE podem usar estes dispositivos com o propósito de aprimorar a sua aprendizagem e com utilizando sua própria estratégia, dependendo de seu objetivo e interesse. Professores podem fazer proveito disso em sala de aula como um suporte para ensinar e planejar suas aulas. Porém, deve-se saber e tomar conhecimento do que pode ou não ser viável, controlando seu uso para fins pedagógicos e alertando seus alunos para influências negativas em seus usos.

\footnotetext{
${ }^{2}$ WhatsApp Messenger is a multiplatform app ('app' is short for 'application') that allows you to exchange messages via cell phone without paying for SMS, just by having a $3 G$ connection or Wi-Fi (Wi-Fi is a popular technology that allows an electronic device to exchange data or connect to the Internet wirelessly using radio waves).

3 " a dictionary where the definition of a word is displayed in the form of a drawing or photograph...".
} 


\section{Aspectos da Aquisição de Linguagem}

Aprendentes de línguas, no contexto da sala de aula e na observação nos usos de aplicativos para aprender uma LE, e também enquanto aprendentes de novos vocabulários, encontram benefícios para a sua própria aprendizagem. Com base nisso, citam-se alguns autores sobre a aquisição de linguagem, as estratégias usadas pelos alunos para adquirir novos vocabulários em LE e como a aprendizagem acontece nesse contexto.

Como mencionado por Sapucaia (2008, p. 2), a definição de aquisição de linguagem seria o "processo natural de assimilação, intuitivo, subconsciente, resultado da interação em situações reais da sociedade humana, em que o aluno participa como sujeito ativo". A linguagem é uma cognição característica do ser humano, que tem a finalidade da comunicação e é uma habilidade inata de produzir palavras significativas ou mesmo apresentar sistemas parcialmente aprendido ou limitado.

Não existem outras espécies conhecidas que sabem lidar e expressar tais processos cognitivos, um sistema limitado de símbolos como sons e vocabulários. Ainda sobre os processos cognitivos, sabe-se que:

As crianças aprendem a linguagem com base em princípios de reforço comportamental associando palavras com significados. As expressões corretas são positivamente reforçadas quando a criança percebe o valor comunicativo das palavras e frases (LEMETYINEN, 2012, p. 1).

Por outro lado, a autora menciona que "as crianças nunca vão adquirir as ferramentas necessárias para processar um número infinito de frases se o mecanismo de aquisição de linguagem dependesse apenas da entrada de linguagem".

Em consonância com esta ideia, a teoria da Gramática Universal (GU), influenciada pela proposta de Noam Chomsky, diz que as categorias gramaticais biológicas (como substantivos e verbos) são inatas e, de acordo com o contexto que a criança está inserida (âmbito familiar, por exemplo) e seu desenvolvimento, ela ativa estas estruturas potenciais e começa a "repetir" as falas dos pais, mesmo que ainda seja errada de acordo com as normas da língua.

Mesmo assim, estudos apontam que ainda não há uma posição exata de como ocorre a aquisição de linguagem, com suas teorias e seus exemplos sendo apresentados. Talvez a teoria da Gramática Universal esteja certa, porque a separação de palavras em categorias ajudaria a criança a entender as diferenciação entre palavras. Por outro lado, talvez a teoria de Skinner esteja certa também, pela repetição de palavras e mostrando seus verdadeiros significados. Acredita-se que ambas podem ser aplicadas e são válidas para o desenvolvimento cognitivo da língua-alvo. 
Assim, a citação dos autores informa que a aquisição de uma LE começa nos primeiros anos da vida de uma criança e como essa complexidade é encontrada em suas habilidades, na qual ela está vinculada dentro dos contextos familiares (a princípio) e sociais, através da interação com as pessoas, ouvindo e interagindo subconscientemente e adquirindo conhecimento prático e funcional da língua falada. Portanto, ligadas a esse ambiente social, as crianças se familiarizam com a estrutura da língua, bem como com as primeiras aquisições de vocabulários, fazendo entender e sendo entendida.

\section{Estratégias de Aprendizagem}

De acordo com Oxford (1990, p. 8), as estratégias de aprendizagem são "ações específicas executadas pelos aprendentes para tornar a aprendizagem mais fácil, mais rápida, mais prazerosa, mais autodirigida, mais eficaz e mais transferível para outras situações"4. Segunda ela, as estratégias de aprendizagem são classificadas em diretas e indiretas.

As estratégias de aprendizagem direta têm contato com a utilização da língua e envolve a memória do aprendente, a sua cognição de compreensão e produção e a compensação em lidar com a língua-alvo mesmo não conhecendo certos vocabulários e estruturas gramaticais. Já as estratégias de aprendizagem indireta são as utilizações da administração do processo de aprendizagem sem o envolvimento direto da língua, envolvendo a metacognição do aprendente (onde avalia, planeja e coordena a sua aprendizagem), a sua motivação efetiva e sociais, que possibilita o aprendente a aprender nos vários contextos sociais (MAGNO E SILVA; SANTOS, 2014).

Meireles (2005, p. 2) acredita que o uso de estratégias de aprendizagem de novos vocabulários traz grandes benefícios para aprendentes, pois eles têm consciência própria do processo de aprendizagem da LE, apresentam esforços, responsabilidades e autonomia para o seu processo de aprendizagem. Enquanto aprendentes de línguas, eles devem ter consciência do correto gerenciamento comunicativo dentro do contexto da interação, demandando o tempo certo e a forma correta para a aprendizagem de novos vocabulários.

Além disso, este autor diz que a aquisição de novos vocabulários começa a partir de um ponto onde o aprendente não sabe nada, até o momento em que ele obtêm informações detalhadas e suficientes. $\mathrm{O}$ autor caracteriza e separa algumas estratégias feitas por eles para chegar ao significado da palavra, entre elas:

a) associação envolvendo a palavra;

b) conceitos;

c) as conotações;

d) as possibilidades de derivação dos vocabulários e as formas como elas são utilizadas em termos sintáticos e morfológicos.

\footnotetext{
${ }^{4}$ Specific actions taken by the learner to make learning easier, faster, more enjoyable, more self-directed, more effective, and more transferrable to new situations.
} 
Essas estratégias são válidas no momento em que o aprendente sente a necessidade de buscar informações mais detalhadas a partir do novo vocabulário lhe apresentado, seja através de dicionários impressos e eletrônicos, seja através da Internet. Não há limites para o conhecimento desta busca e temos várias maneiras de obter esse conhecimento atualmente, por isso afirma-se que a aprendizagem se torna fácil e eficaz.

As estratégias utilizadas pelos alunos permitem-lhes torná-los autodirigidos, ou seja, tomar medidas específicas e podem ser flexíveis e conscientes de sua parte. Sobre essas estratégias:

No momento em que o ensino dá condições aos aprendizes de L2 de conhecerem estas estratégias e de conviverem com elas, de certa maneira, permite também que esse aprendiz acesse as estratégias que melhor lhe convier, além de promover uma conscientização de seu próprio processo de aprendizagem da L2. E a partir do momento que esse aprendiz se conscientiza de sua aprendizagem, parece que ele passa a ter um senso crítico muito mais aguçado, percebendo, assim, o que funciona ou não com ele, detectando, dessa forma, suas falhas com maior facilidade e se preparando adequadamente para transpor barreiras no processo de aprendizagem da L2 (MEIRELES, 2005, p. 9).

Dessa maneira, os alunos podem ter consciência do que pode ser aproveitável e o que não pode ser, no sentido de organização de aprendizagem, pois, com o fácil acesso às informações hoje em dia, ele procura aquilo que melhor lhe satisfaça para o aprendizado de um novo vocabulário em LE, usando estratégias próprias e instrumentos adequados para alcançar seus objetivos.

Portanto, acredita-se que os esforços individuais de cada aprendiz da LE são os principais fatores para que eles obtenham sucesso, tendo em vista que nesta perspectiva o aprendente apresenta maior interesse na abordagem e controle de sua própria aprendizagem e uso da língua. Acredita-se também que todas as estratégias de aprendizagem são válidas e apropriadas, uma vez que é resultante em um melhor desempenho da competência linguística e dar a ele maior autoconfiança e responsabilidade, deixando de ser o agente passivo da sala de aula e agindo como agente ativo em seu processo aprendizagem.

A aprendizagem de línguas requer tempo e, sendo praticada, vai sendo adquirida gradualmente, assim como aprenderam a língua nativa, encontrando, ouvindo, escrevendo e falando as palavras. Na perspectiva da aquisição de vocabulário, ao submeter aprendentes à instrução prática e significativa, menos erros podem ter na linguagem e pode-se encorajá-los a ser autônomos para a sua própria aprendizagem na sala de aula.

\section{Método de pesquisa}

Sendo uma pesquisa qualitativa e quantitativa de estudo de caso, ela ocorreu em uma turma de curso livre de segundo nível de inglês na Universidade Federal do Pará. O curso é disponível para a comunidade em geral, contendo em média mais de 2.000 estudantes por 
semestre e o único requisito para cursar é ter o ensino médio completo. Os participantes da pesquisa foram alunos diversificados no que diz respeito ao gênero e idade. No total, 18 alunos participaram desta pesquisa.

Os instrumentos de pesquisa utilizados foram o termo de consentimento de participação da pesquisa e questionário de pesquisa. O termo de consentimento de participação da pesquisa continha informações sobre a pesquisa em geral, assim como o propósito da mesma e dados relevantes. Além disso, os participantes puderam preencher seus dados pessoais e criar um pseudônimo (caso houvesse a necessidade de citar o aluno nesta pesquisa), assinando ao final. $\mathrm{O}$ questionário de pesquisa continha perguntas estruturadas (fechadas), semiestruturadas (semifechadas) e não estruturadas (abertas), contendo um total de dez perguntas.

Os procedimentos de pesquisa adotados foram elaborados em seis passos: primeiro, levantamento da fundamentação teórica, com as discussões dos tópicos e do tema apresentado. Em seguida, a elaboração do termo de consentimento de pesquisa e do questionário de pesquisa. Depois, houve pedido de autorização junto com a coordenação do curso para aplicação da pesquisa, onde foi apresentado os objetivos da mesma. Seguidamente, houve pedido de autorização junto com o professor da turma escolhida, sendo logo em seguida apresentado à turma a pesquisa e os procedimentos relativos a coleta de dados junto com a distribuição dos termos de consentimento de pesquisa, onde os alunos ficaram cientes e foi garantido liberdade em participar ou não. Depois, os questionários foram distribuídos para quem participou da pesquisa. E por último, com a coleta de dados, começou-se a análise dos dados.

\section{Análise e discussão dos dados}

A primeira pergunta do questionário foi "Você já estudou em algum outro curso de inglês?”. Os resultados podem ser vistos nas tabelas abaixo:

\begin{tabular}{cc}
\hline Resposta & Quantidade \\
\hline SIM & 8 \\
NÃO & 10 \\
\hline TOTAL & 18
\end{tabular}

TABELA 1 - respostas pergunta 1

\begin{tabular}{cc}
\hline Por quanto tempo & Quantidade \\
\hline 1 semestre & 2 \\
2 semestres & 2 \\
1 ano & 1 \\
1 ano e 1 semestre & 2 \\
2 anos & 1 \\
\hline TOTAL & 8 \\
TABELA 2 - respostas da pergunta 1: opção "sim"
\end{tabular}


Como podemos perceber, a maioria dos estudantes já possuem um conhecimento da língua antes de entrar no curso. Isso pode demonstrar facilidade na aprendizagem durante o curso e talvez eles já saibam como praticar a partir de suas próprias estratégias de aprendizagem.

A segunda pergunta do questionário foi "Você já fez algum curso de informática?". Os resultados podem ser vistos nas tabelas abaixo:

\begin{tabular}{cc}
\hline Resposta & Quantidade \\
\hline SIM & 14 \\
NÃO & 4 \\
\hline TOTAL & 18 \\
TABELA $3-$ respostas pergunta 2
\end{tabular}

\begin{tabular}{cc}
\hline Que ferramentas dominantes & Quantidade \\
\hline MS Office & 7 \\
Internet & 7 \\
\hline
\end{tabular}

TABELA 4 - respostas da pergunta 2: opção "sim"

O que podemos analisar é que a maioria dos estudantes tem participado de um curso de computação, tendo o domínio de alguns programas como Microsoft Office e Internet. Possivelmente estes estudantes também têm conhecimento sobre aplicativos, programas e dispositivos. Assim, a importância de ter um curso de informática se torna importante porque muitas instituições de ensino requeremde seus usuários o conhecimento e o domínio de tal curso para a realizaçãode tarefas ou pesquisarem materiais online. Isto é um importante aspecto para se buscar conhecimento além do da sala de aula e dos livros impressos, pois aprendentes têm a oportunidade de aprender com praticidade e com uma gama de materiais disponíveis na Internet.

A terceira pergunta do questionário foi "Dentre os itens relacionados abaixo, quais você possui?". O resultado pode ser visto na tabela abaixo:

\begin{tabular}{cc}
\hline Resposta & Quantidade \\
\hline Computador pessoal (Desktop) & 7 \\
Smartphone & 12 \\
Notebook & 16 \\
Celular comum & 6 \\
Nenhuma resposta & 0 \\
\hline
\end{tabular}

TABELA 5 - respostas pergunta 3

Nesse sentido, a maior parte dos alunos possuem instrumentos tecnológicos e usam dispositivos, o que podemos supor que a utilização deles servem para atividades específicas e talvez para sua própria aprendizagem, tendo acesso à Internet. 
Kern (2006, p. 1) diz que a demanda de usuários para tais equipamentos cresce todos os dias e novos equipamentos estão sendo criados em um processo rápido e contínuo. No caso do resultado desta terceira pergunta, isso mostra claramente que alunos estão cientes da necessidade de uso desses equipamentos nos dias atuais e tendem a aprender melhor com a variedade de recursos, tarefas ou aplicativos que eles podem proporcionar. Isso também confirma o resultado da segunda pergunta sobre o conhecimento de um curso de informática, pois eles podem implementar e pôr em prática os conhecimentos adquiridos.

A quarta pergunta do questionário foi "Que recursos abaixo você utiliza para auxiliálo(a) na aprendizagem da língua inglesa, sem que seja preciso que o professor lhe peça para utilizá-los?". Nesta pergunta, os alunos poderiam escolher mais de uma opção e o resultado pode ser visto na tabela a seguir:

\begin{tabular}{cc}
\hline Resposta & Quantidade \\
\hline Computador & 10 \\
Smartphone & 12 \\
Dicionário impresso & 6 \\
Livro didático obrigatório & 7 \\
Livro de gramática & 2 \\
Outros & 3 \\
\hline
\end{tabular}

TABELA 6 - respostas pergunta 4

Analisando os resultados da tabela seis, a maioria dos alunos usam smartphone ou telefone celular como auxílio à aprendizagem da língua inglesa e alguns deles usam computador. Então, nota-se que alunos usam aplicativos nesses dispositivos como estratégia para aprender inglês e, talvez, estes aplicativos são ferramentas importantes e facilitadoras por causa de sua fácil manipulação e resultados rápidos.

Nesse contexto, a maioria de estudantes usam o computador e smartphone como ferramentas de aprendizagem da língua, além de poderem contar com outros recursos, tais como dicionários impressos e livros da gramática.

Os alunos que responderam "outros" mostraram que eles têm a oportunidade de estudar a língua através de suas próprias estratégias através de aplicativos de tradução, filmes, música e livros, não importa se ele pode resolver dúvidas na língua ou apenas para estudar por conta própria. Estes resultados mostram a possibilidade de pesquisar e aprender novos vocabulários em inglês e são alguns recursos importantes.

Em consonância com esta quarta pergunta, foram elaboradas perguntas complementares, pela qual foi "Caso tenha marcado as opções computador, smartphone ou celular, que ferramentas você utiliza para auxiliá-lo(a) no aprendizado da língua inglesa, sem que seja preciso que o professor lhe peça para utilizá-los?”. O objetivo desta pergunta complementar foi saber, em específico, quais programas, aplicativos ou ferramentas que os alunos utilizavam em computador e smartphone, sem a intervenção do professor, sendo que os alunos deveriam marcar as opções propostas e descrever quais tipos de programas, 
aplicativos ou ferramentas utilizavam, caso se a resposta fosse "Outro". Os resultados podem ser vistos nas tabelas seguintes:

\begin{tabular}{cc}
\hline Opção & Quantidade \\
\hline $\begin{array}{c}\text { Programa de instalação em } \\
\text { computador pessoal } \\
\text { sem acesso à Internet }\end{array}$ & 3 \\
$\begin{array}{l}\text { Programa de instalação em } \\
\text { computador pessoal (desktop ou laptop) } \\
\text { que necessita de acesso à Internet }\end{array}$ & 5 \\
$\begin{array}{l}\text { Sites específicos da Internet em um } \\
\text { computador pessoal (desktop ou laptop) } \\
\text { usando um navegador }\end{array}$ & 7 \\
$\quad \begin{array}{l}\text { Aplicativo de instalação } \\
\text { em smartphone ou celular } \\
\text { sem acesso à Internet }\end{array}$ & 2 \\
Aplicativo de instalação em \\
smartphone ou celular \\
que necessita de acesso à Internet
\end{tabular}

TABELA 7 - respostas pergunta suplementar

A maioria dos alunos preferem usar aplicativos em smartphone ou telefone celular e sítios específicos no computador, usando o navegador da web e conexão com a Internet. Os resultados abaixo mostram que tipo de aplicativos os alunos geralmente usam em computadores e smartphones ou telefones celulares:

\begin{tabular}{cc}
\hline Aluno $^{5}$ & Resposta pessoal \\
\hline Many & Dicionário \\
Nico & TOEFL ITP (simulador em CD-ROM) \\
Walysson & Dicionário Larausse \\
\hline
\end{tabular}

TABELA 8 - pergunta suplementar: opção "Programa de instalação em computador pessoal (desktop ou laptop) sem acesso à Internet"

De acordo com a tabela oito, dois estudantes escolheram dicionário como aplicativo instalado em computadores que não necessitam de acesso à Internet. Esta opção pode ser viável para estudar a língua a partir de uma aplicativo específico, tendo informações e recursos diversificados (como a possibilidade de escutar o vocabulário) com o propósito da prática da língua.

${ }^{5}$ Os nomes dos estudantes mencionados nesta pesquisa são pseudônimos. 


\begin{tabular}{cc}
\hline Aluno & Resposta pessoal \\
\hline Ricardo & Google Translator \\
Eva & Translator \\
Jacqueline & Sítios de tradução online \\
Manu & Aplicativo (tradutor, Vagalume) \\
Isabella & Não respondeu \\
\hline TABELA 9 - pergunta suplementar: opção "Programa de instalação em computador pessoal (desktop
\end{tabular}

TABELA 9 - pergunta suplementar: opção "Programa de instalação em computador pessoal (desktop ou laptop) que necessita de acesso à Internet"

A tabela nove mostra que a maioria dos estudantes preferem usar aplicativos em computadores que tenham a possibilidade de traduzir algumas palavras do inglês para os seus significados, mas isso requer conexão com a Internet. Porém, alguns desses aplicativos, como Google Translator requer conexão com a Internet para escutar as palavras ou frases na LE.

\begin{tabular}{cc}
\hline Aluno & Resposta pessoal \\
\hline Walysson & My English Online; Lyrics English; Googletranslator \\
Nico & Youtube $;$ Cifra club; Vagalume \\
Eloah & Google translator \\
Torres & Songs; Dynamic in English \\
Emanuelle & My English Online \\
Jacqueline & Google; Bing \\
Ricardo & Não respondeu \\
\hline
\end{tabular}

TABELA 10 - pergunta suplementar: opção "Sites específicos da Internet em um computador pessoal (desktop ou laptop), usando um navegador (Explorer, Firefox, Chrome)"

A tabela dez mostra que os estudantes preferem usar Google Translator, My English Online, letras de músicas e vídeos do sítio Youtube. Sendo assim, eles acessam diferentes recursos em sítios para praticar o inglês através de aplicativos de navegação e estes sítios promovem ferramentas alternativas e materiais diversos para estudar a língua.

\begin{tabular}{cc}
\hline Aluno & Resposta pessoal \\
\hline Walysson; Eloah & GoogleTranslator \\
\hline TABELA 11 - pergunta suplementar: opção "Aplicativo de instalação em smartphone ou celular sem \\
acesso à Internet"
\end{tabular}

De acordo com a tabela onze, dois estudantes preferem usar o aplicativo Google Translator instalado em smartphone, com o propósito de pesquisar novas palavras e frases da língua inglesa, sem a necessidade de conexão com a Internet. Isto responde a hipótese levantada neste trabalho, de que é comum o uso de sítios e aplicativos instalados em computadores e smartphones para a aprendizagem de novos vocabulários. 


\begin{tabular}{cc}
\hline Aluno & Resposta pessoal \\
\hline Lika & Duolingo; translator \\
Riquelme & Translator \\
Stive Pizza & Google translator \\
Adanielie & Duolingo; LinguaLeo \\
Isabella & Translator \\
Manu & Aplicativos envolvendo músicas \\
Walysson & Google translator \\
Ricardo & Não respondeu \\
\hline
\end{tabular}

TABELA 12 - pergunta suplementar: opção "Aplicativo de instalação em smartphone ou celular que necessita de acesso à Internet"

Analisando a tabela doze, a maioria dos estudantes acessam aplicativos disponíveis em computadores e smartphones, usando, por exemplo, sítios da Internet como Google Translator e Duolingo, utilizados através de navegadores como Internet Explorer, Firefox e Google Chrome. A maioria dos estudantes também usam aplicativos em smartphones como Duolingo, WhatsApp e Youtube.

Assim, como resultado, estudantes de inglês usam aplicativos para aprender a língua, seja através de aplicativos como navegador de Internet, seja através de aplicativos instalados em smartphones ou telefones celulares. É confirmado na base teórica que entre as muitas vantagens que podemos encontrar com a realização destes avanços é o fato de aprendermos hoje, por nós mesmos, qualquer LE através de vários sítios, com exercícios específicos para cada habilidade e uma interação motivacional incrível.

A quinta pergunta do questionário foi "Levando em consideração a pergunta $n^{\circ} 4$, em quais lugares você utiliza essas recursos?", e os alunos poderiam escolher mais de uma opção. O resultado pode ser observado na tabela a seguir:

\begin{tabular}{cc}
\hline Resposta & Quantidade \\
\hline Somente na sala de aula & 3 \\
Em casa & 16 \\
Outros locais & 7 \\
\hline
\end{tabular}

TABELA 13 - respostas pergunta 5

De acordo com a tabela treze, a maioria dos estudantes preferem usar aplicativos em seus dispositivos em casa. Entre os estudantes que escolheram "outros locais", as respostas foram no trabalho, na sala de aula, em casa, na livraria da universidade e as vezes quando necessário. Como se percebe, estudantes possuem o hábito de usar seus computadores e smartphones fora da sala de aula, o que confirma que eles são usuários dessas tecnologias e podem facilmente aprender através deles. Além disso, isso não significa que eles os usem somente dentro da sala de aula e pode ser considerado uma forma viável para pesquisas de palavras novas que eles desconhecem ou fazer alguma tarefa específica pedida pelo professor. 
A sexta pergunta do questionário foi "Quando você se depara com uma palavra nova na língua inglesa, como você procura seu significado?", e os alunos poderiam escolher mais de uma opção. O resultado pode ser observado na tabela a seguir:

\begin{tabular}{cc}
\hline Opção & Quantidade \\
\hline Pergunta diretamente ao professor & 9 \\
Busca o significado em um dicionário impresso & 7 \\
$\begin{array}{c}\text { Busca o significado em um programa } \\
\text { instalado no seu computador pessoal (desktop ou laptop) } \\
\text { sem acesso à Internet }\end{array}$ & 1 \\
Busca o significado em um programa & 7 \\
instalado no seu computador pessoal (desktop ou laptop) \\
que necessita de acesso à Internet \\
$\begin{array}{c}\text { Busca o significado em um site no seu } \\
\text { computador pessoal (desktop ou laptop) }\end{array}$ \\
$\begin{array}{c}\text { usando um navegador (Explorer, Firefox, Chrome) } \\
\text { Busca o significado em um aplicativo } \\
\text { instalado no seu smartphone } \\
\text { sem acesso à Internet }\end{array}$ \\
$\begin{array}{c}\text { Busca o significado em um aplicativo } \\
\text { instalado no seu smartphone }\end{array}$ \\
$\begin{array}{c}\text { que necessita de acesso à Internet } \\
\text { Busca o significado em um site }\end{array}$ \\
no seu smartphone \\
usando um navegador (Explorer, Firefox, Chrome)
\end{tabular}

TABELA 14 - respostas pergunta 6

Neste resultado, a maioria dos estudantes pedem auxílio do professor para saber o significado de um novo vocabulário na língua inglesa. Por outro lado, alguns usam programas e aplicativos em computadores e smartphones para saber o significado delas.

Então, os participantes preferem perguntar diretamente ao professor e pode-se supor que eles não possuem o hábito de pesquisar por conta própria e ainda possuem a dependência do professor da sala de aula. Além disso, quando encontram o significado delas, não possuem certeza do sentido delas e perguntam diretamente a ele.

Sabendo disto, podemos perceber que estudantes utilizam algumas estratégias para aprender novos vocabulários durante o curso, mesmo ainda apresentando certa dependência do professor para certas dúvidas. Como Meireles (2005, p. 9) relata, o uso de certas estratégias para a aprendizagem de novos vocabulários trazem grandes benefícios aos 
estudantes, possuindo seus próprios objetivos, interesses e níveis durante este processo, com esforço, responsabilidade e autonomia.

A sétima pergunta do questionário foi "Através da(s) opção(ões) que você marcou na pergunta anterior, você sempre encontra a solução para o significado de uma palavra nova?". O resultado obtido está na tabela a seguir:

\begin{tabular}{cc}
\hline Resposta & Quantidade \\
\hline SIM & 16 \\
NÃO & 2 \\
\hline TOTAL & 18 \\
TABELA $15-$ respostas pergunta 7 &
\end{tabular}

Entre os diferentes recursos que estudantes acessam para encontrar o significado de uma palavras em inglês, praticamente todos os satisfazem enquanto isso. Talvez isso mostre que essas ferramentas podem oportunizar o aumento dos resultados dos processos de aprendizagens, pois muitos aplicativos são avançados e, conforme são atualizados periodicamente, podem dar à seus usuários grande auxílio nas pesquisas.

Podemos dizer que mesmo se a maioria dos estudantes perguntam ao professor pelo significado da palavra, eles possivelmente recebem resultado positivo e informações precisas, pois o professor pode contextualizar o significado delas através de vários exemplos de uso, dando mais ênfase na compreensão.

A oitava pergunta do questionário foi "Os seus professores de inglês incentivam você a usar computadores e/ou smartphones para procurar significados de palavras?". O resultado obtido está na tabela a seguir:

\begin{tabular}{cc}
\hline Resposta & Quantidade \\
\hline SIM & 10 \\
NÃO & 8 \\
\hline TOTAL & 18 \\
TABELA & 16 - respostas pergunta 8
\end{tabular}

Com este resultado, a maioria dos estudantes dizem que professores os encorajam a usarem essas ferramentas na turma de inglês, enquanto que outros estudantes dizem que o professor não os encoraja. Sendo assim, talvez o professor aceite esses dispositivos como recursos de ensino e que eles podem ser importante ferramentas para auxílio na aprendizagem da língua inglesa. Por outro lado, oito estudantes talvez tenham respondido negativamente porque professores atuais e professores antigos nunca os incentivaram nesse sentido e isso pode ter uma influência sobre a aprendizagem não só de novos vocabulários, mas da língua inglesa no geral.

A nona pergunta do questionário foi "Você realizou alguma tarefa dentro ou fora de sala de aula em que o professor pediu explicitamente para que você achasse o significado de 
uma palavra em inglês em um computador e/ou smartphone?". O resultado pode ser visto na tabela abaixo:

\begin{tabular}{cc}
\hline Resposta & Quantidade \\
\hline SIM & 4 \\
NÃO & 14 \\
\hline TOTAL & 18
\end{tabular}

TABELA 17 - respostas pergunta 9

Como análise, os estudantes relataram que professores não têm o hábito de pedir para que eles procurem pelo significado de uma palavra nova do inglês, tanto dentro quanto fora da sala de aula. Talvez isso se explique pelo fato de que professores vão para a sala de aula já com as aulas planejadas e já conheçam o significado dos vocabulários novos que repassarão para a turma.

Nesse contexto, acredita-se que o professor deve encorajar seus alunos durante a aprendizagem da língua e planejar atividades em que eles possam aprender novos vocabulários de forma incentivadora e por conta própria. Isso possibilita que os alunos encontrem suas próprias estratégias de aprendizagem, pois ganham responsabilidade e atitudes diante de algo que ainda não conhecem e buscam informações a respeito. Diante destas ferramentas, eles ganham motivação e conhecimento para aprender a língua, tendo disponível uma gama de materiais autênticos (SELJAN; BERGER; DOVEDAN, 2004).

A décima pergunta do questionário foi "Escreva abaixo a sua experiência e opinião sobre como o computador ou smartphone tem te ajudado a aprender inglês", sendo uma pergunta aberta e que poderiam expressar suas próprias opiniões. O resultado pode ser visto na tabela a seguir:

\begin{tabular}{cc}
\hline Resposta & Quantidade \\
\hline $\begin{array}{c}\text { Computador ou smartphone } \\
\text { com conexão de Internet } \\
\text { são essenciais para a aprendizagem da língua }\end{array}$ & 8 \\
$\begin{array}{c}\text { Dispositivos são mais práticos } \\
\text { e fáceis de carregá-los } \\
\text { para qualquer lugar }\end{array}$ & 4 \\
Não respondeu & 6 \\
\hline TOTAL \\
TABELA 18 - respostas pergunta 10
\end{tabular}

De acordo com o resultado, estudantes usam computadores e smartphones como recursos essenciais na aprendizagem de língua inglesa, sempre com aplicativos com acesso à Internet. 
Além de serem bons recursos, o uso desses dispositivos tem se mostrado mais prático e uma forma fácil de uso, pois eles podem ser levados para qualquer lugar, seja ele no bolso, seja ele em mochilas. Em contraste, na maioria das vezes, outros materiais como dicionários impressos e livros são carregados em mochilas ou bolsas. Entre as respostas, ainda houveram comentários específicos sobre aplicativos em sítios que estudantes usam mais, como $M y$ English Online e Google Translator, com o propósito de pesquisar vocabulários ou sentenças novas. Percebe-se também que a maioria dos estudantes usam sítios (como www.translate.google.com) como hábito, com a finalidade (além de achar significados de palavras) de procurar a pronúncia correta.

\section{Conclusão}

Esta pesquisa provou ser de grande importância para conhecer o perfil do aluno em sala de aula e o que eles fazem para melhorar sua própria aprendizagem da língua inglesa. Com a realização desta pesquisa, confirma-se que eles podem ser encorajados a encontrar significados de novos vocabulários em diferentes recursos, como através da Internet, programas, aplicativos, dicionários impressos etc. Ao mesmo tempo demonstraram suas próprias estratégias de aprendizagem para procurar novos vocabulários.

Os alunos foram mais autônomos, que mostraram ter experiência ampla do assunto e ter conhecimento de alguns recursos que podem ajudá-los durante a aprendizagem de novas palavras em inglês. Eles gostam de usar recursos como programas de computador e aplicativos em smartphones, que são recursos que podem ser utilizados sem a intervenção do professor. Também percebeu-se que os alunos geralmente têm o conhecimento de tecnologias atuais e transparecem que, quanto mais a tecnologia evolui nesses dispositivos, mais gostam de usá-los como uma ferramenta para a aprendizagem de LE.

Embora muitos professores não tenham conhecimento desses dispositivos e não saibam usá-los como ferramenta de ensino em sala de aula, o encorajamento deles é importante para a aprendizagem de seus alunos, pois assim terão oportunidade de procurar e encontrar fontes de estudos por conta própria. Hoje em dia temos vários recursos disponíveis e facilmente acessíveis e espera-se que a motivação dos alunos cresça durante este processo, melhorando e mostrando novas características com o tempo.

Estas ferramentas atuais podem ampliar e melhorar a educação, otimizar o tempo na sala de aula, facilitar a aprendizagem de alunos, melhorar a comunicação e a aprendizagem no ensino. Então, isso pode ser um apoio para mostrar como os professores poderiam inserir estes aspectos em seus planos de aulas. Por outro lado, professores têm que estar alerta para o uso adequado desses dispositivos na sala de aula, sabendo lidar com o mau uso e uso inadequado de alguns recursos e materiais encontrados neles.

No geral, nota-se que o uso de aplicativos são valorizados para estudantes e professores, pois estamos caminhando para uma era digital que está sendo modificada, melhorada e evoluindo constantemente e com o crescente número de usuários de todas as estruturas educacionais. Espera-se também que professores saibam lidar com esse novo 
ensino na sala de aula, aproveitando-o e sabendo aplicar, dirigir, dar apoio e motivar seus alunos a encontrarem outros recursos além dos da sala de aula.

\section{Referências}

FERREIRA, L. C. R. Whatsapp Messenger:

a tool to motivate students in English language writing. 2013. $36 \mathrm{f}$. Trabalho de Conclusão de Curso (Licenciatura em Línguas Inglesa) - Instituto de Letras e Comunicação, Universidade Federal do Pará, Belém, 2013.

HUBBARD, P. Computer Assisted Language Learning. v. 1: Foundations of CALL. Critical Concepts in Linguistics Series. New York: Routledge, 2009.

KERN, R. Perspectives on technology in learning and teaching languages. University of California. Berkeley, 2006. Disponível em: <http://wha.arizona.edu/group/ariew/slat596/Kern_tech.pdf>. Acesso em: 05 abr. 2016.

LEFFA, V. J. A aprendizagem de línguas mediada por computador. In: Vilson J. Leffa. (Org.). Pesquisa em linguística aplicada: temas e métodos. Pelotas: Educat, 2006.

LEMETYINEN, H. Language Acquisition. SimplyPsychology. 2012. Disponível em: <http://www.simplypsychology.org/language.html>. Acesso em: 23 set. 2016.

MAGNO E SILVA, W.; SANTOS, E. M. Promovendo a autonomia e a motivação: o papel do conselheiro linguageiro. Horizontes de Linguística Aplicada. Asa Norte, Ano 13, n. 1, p. 89-105, 2014. Disponível em:

<http://periodicos.unb.br/index.php/horizontesla/article/viewFile/11742/10746>. Acesso em: 14 jun. 2016.

MORAN, J. M. Tendências da educação online no Brasil. Educação humanista inovadora. Educação a distância. 2005. Disponível em: < http://www.eca.usp.br/moran/tendencias.htm>. Acesso em: 07 abr. 2016.

PORTO, F. Aplicativos Mobile: Definições, História e Previsões. Blog TecTriade Brasil. São Paulo, 2012. Disponível em: <http://tectriadebrasil.com.br/blog/mercado-de-midiassociais-blog/aplicativos-mobile-definicoes-historia-e-previsoes/>. Acesso em: 15 fev. 2016.

RODRIGUES, S. Computador, uma ferramenta educacional. Um espaço educacional. Governador Valadares, 2005. Disponível em:

<sidiney.awardspace.com/port/files/prodecurso-infoduc.pdf〉. Acesso em: 06 abr. 2016.

SAPUCAIA, M. Aquisição e Aprendizado: dois processos no ensino de uma segunda. Universidade Presbiteriana Mackenzie. São Paulo, 2008. Disponível em:

<http://www.mackenzie.com.br/fileadmin/Graduacao/CCL/projeto_todasasletras/inicie/Miche leSapucaia.pdf >. Acesso em: 17 ago. 2016.

SELJAN, S.; BERGER, N.; DOVEDAN, Z. Computer-Assisted Language Learning (CALL). In: Proceedings of the 27th International Convention MIPRO 2004: MEET + HGS. 2004. Disponível em: <http://dzs.ffzg.unizg.hr/text/call.pdf>. Acesso em: 18 ago. 2016. 
